\title{
COMPARAÇÃO DO CRESCIMENTO E DO DESGASTE DO CASCO EM BOVINOS TAURINOS E ZEBUÍNOS
}

\author{
RATES OF HOOF GROWTH AND WEAR IN ZEBUINE AND TAURINE CATTLE
}

\author{
Rüdiger Daniel Ollhoff $^{1}$ Enrico Lippi Ortolani ${ }^{2}$
}

\section{RESUMO}

No presente trabalho, mediram-se o crescimento e o desgaste do casco dos quatro dígitos laterais, em duas posições (dorsal e lateral), em quatro garrotes da raça Jersey e quatro da raça Gir, mantidos em "tie-stall", sobre piso de cimento recoberto por alta camada de maravalha. O trabalho transcorreu no período de novembro de 1997 a abril de 1998. As medidas de crescimento e desgaste do casco foram obtidas empregando-se a técnica clássica descrita por HAHN et al. (1986). Não ocorreram diferenças significativas no crescimento e no desgaste dos cascos entre as raças estudadas, assim como entre as unhas dos cascos dos membros anteriores e posteriores. Em ambas as raças, foram constatados maiores desgaste e crescimento da região lateral (lado abaxial) do casco, em relação à região dorsal, indicando que grande parte do contato e sustentação do corpo ocorre na área lateral do casco. A apara funcional acelera o crescimento do casco, porém não altera a taxa de desgaste.

Palavras-chave: bovino, casco, crescimento, desgaste, medidas.

\section{SUMMARY}

Rates of hoof growth and wear, on both dorsal and lateral surfaces of front and rear outside claws, were measured in four Jersey and four Gir yearling steers kept on a tie-stall system on a concrete ground covered by deep layer of sawdust. Measurements were taken from November 1997 to April 1998 according to the classical technique described by HAHN et al. (1986). No significant differences in the growth and wear of the claws were found between the two breeds. There was no significant difference of growth and wear rates between front and rear claws. Horn of the lateral walls grew and wore faster in taurine and zebuine cattle, indicating that most of the weightbearing and contact to the soil is given through this region. Functional trimming increases claw horn growth but does not interfere with wear rates.

Key words: bovine, claw, growth, wear, measurements.

\section{INTRODUÇÃO}

A inspeção do estojo córneo pode fornecer importantes informações a respeito do manejo nutricional e histórico clínico recente de um bovino (GREENOUGH \& WEAVER, 1997). Enfermidades metabólicas, tais como acidose láctica ruminal, laminites e carências extremas de certos nutrientes, podem promover alterações na qualidade e no crescimento dos cascos, através de modificações temporárias do tecido primordial germinativo deste tegumento, na lâmina coriônica e no "stratum basale" do perióplio, na coroa do casco. A presença de tecido córneo de má qualidade constitui um fator predisponente para o desenvolvimento de outros processos infecciosos ou degenerativos futuros, que gerarão claudicação nos bovinos acometidos. A frequiência de problemas locomotores é mais alta em bovinos mantidos em sistemas de criação confinados e semiconfinados que em sistemas extensivos (MGASSA et al. 1988; RIBEIRO et al. 1992).

Bovinos criados em confinamento que conseguem manter um balanço adequado entre crescimento e desgaste do estojo córneo são menos sujeitos a problemas de cascos, tais como úlcera de sola, doença da linha branca e pododermatite séptica (MANSON \& LEAVER 1988).

Numa revisão sobre crescimento e desgaste dos cascos, VERMUNT \& GREENOUGH (1995) afirmaram que não existe influência racial sobre essas variáveis. Por outro lado, MURPHY \& HANNAN (1986) compararam garrotes das raças

\footnotetext{
${ }^{1}$ Médico veterinário, PhD., bolsista CNPq, Departamento de Clínica Médica, Faculdade de Medicina Veterinária e Zootecnia (FMVZ), Universidade São Paulo (USP). Rua José Francisco Dalledone 237, Sobrado 8, 82200-250, Curitiba, PR. Autor para correspondência.

${ }^{2}$ Médico veterinário, PhD., Professor Associado, Departamento de Clínica Médica, FMVZ-USP. Recebido para publicação em 29.11.99. Aprovado em 07.06.
} 
Holandesa e Hereford, detectando maiores crescimento e desgaste na primeira raça. Contudo, deve-se ressaltar que os estudos supracitados sobre esse assunto foram realizados apenas em bovinos de raças européias (taurinos). Até o momento, não foram encontrados quaisquer outras avaliações comparativas, na literatura, entre raças zebuínas e taurinas, sendo essa uma lacuna a ser preenchida. Nessa mesma revisão, VERMUNT \& GREENOUGH (1995) destacaram as marcantes influências anatômicas, fisiológicas, estacionais, nutricionais, ambientais e de manejo sobre o crescimento e desgaste dos cascos dos bovinos.

Em sistemas de criação intensiva de bovinos, em especial de raças leiteiras, o corte de casco preventivo é salutar e necessário para diminuir a frequiência de problemas locomotores, assim como o descarte de animais por esses motivos (GREENOUGH \& WEAVER, 1997). Um único trabalho estudou a influência da apara de casco sobre o crescimento e o desgaste dos mesmos, concluindo que essa manobra estimula o crescimento córneo ocorrendo o inverso com o desgaste (MANSON \& LEAVER 1988). Mesmo assim, maiores estudos são necessários para comprovar estas constatações. O mesmo aplica-se à taxa de crescimento e de desgaste entre os cascos dos membros anteriores e posteriores, havendo autores, CLARK \& RAKES (1982) e TRANTER \& MORRIS (1992), que não constataram diferenças, enquanto que HAHN et al. (1986) encontraram maiores crescimento e desgaste nos cascos dos membros posteriores.

O objetivo do presente trabalho é estudar, comparativamente, a influência racial e de apara corretiva do estojo córneo sobre a taxa de crescimento e de desgaste dos cascos de garrotes das raças Jersey e Gir criados em condições intensivas. com $15 \mathrm{~cm}$ de altura, trocada a cada três dias. Diariamente, era retirada, de forma seletiva, o excesso de fezes da região posterior da baia e, dependendo do caso, pequenas porções de maravalha colocadas sobre a cama existente. Os bebedouros tinham controle central e não apresentaram vazamento durante o experimento. Uma vez por semana, os garrotes eram soltos num solário, com piso de cimento, por um período de quatro horas. A alimentação consistia de $70 \%$ da matéria seca (MS) de feno de capim coast-cross (Cynodon dactylum (L) Pers) e 30\% da MS de ração concentrada ( $75 \%$ farelinho de trigo e $25 \%$ de farelo de soja). Os animais recebiam diariamente, por cabeça, $40 \mathrm{~g}$ de um suplemento mineral comercial, contendo sal comum e os macro- e microelemenotos essenciais. A ingestão de matéria seca diária correspondia a $2,7 \%$ do peso vivo dos garrotes.

$1^{\circ}$ Experimento - Foram avaliados o crescimento e o desgaste normais do casco de garrotes das duas supracitadas raças. A primeira medida foi tomada no dia 14 de novembro de 1997 e, 60 dias após, foi determinada a segunda mensuração. Mediram-se todas as unhas laterais dos quatro membros de cada animal. Para a mensuração e o cálculo do crescimento e do desgaste dos cascos foi empregada a técnica descrita por HAHN et al. (1986), a qual recomenda a marcação da muralha do casco em dois pontos específicos (dorsal e lateral) em duas ocasiões diferentes (Figura 1 e 2). Ao invés do ferro de solda, preconizada pela técnica original, a marcação foi realizada com o emprego de uma broca de aço com 1,9mm de diâmetro a qual era acoplada a uma furadeira Minimot 40/E de alta rotação (20.000rpm). A primeira marca foi fresada no estojo córneo a um centímetro da linha do perióplio, aprofundando-se a broca o suficiente para permitir uma boa identificação, sem, no entanto, atingir o tecido vivo (Figura 1).

\section{MATERIAL E MÉTODOS}

Foram utilizados, no primeiro experimento, oito garrotes, quatro da raça Jersey e quatro Gir, com um ano de idade e pesando entre 140 e $170 \mathrm{~kg}$. No segundo experimento, foram utilizados apenas os quatro garrotes da raça Jersey. Os animais foram criados extensivamente até os seis meses de idade e, em seguida, foram desmamados e mantidos estabulados, em baias individuais, num sistema de "tie-stall" (presos em correntes), sobre um piso de cimento, recoberto por cama de maravalha,

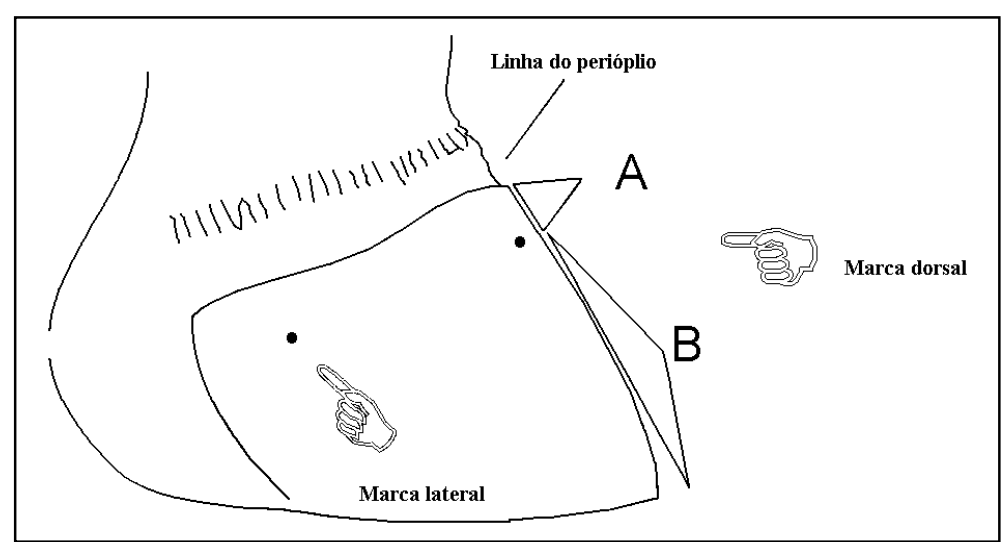

Figura 1 - Esquema da face lateral de casco bovino, na primeira marca realizada em novembro de 1997. 


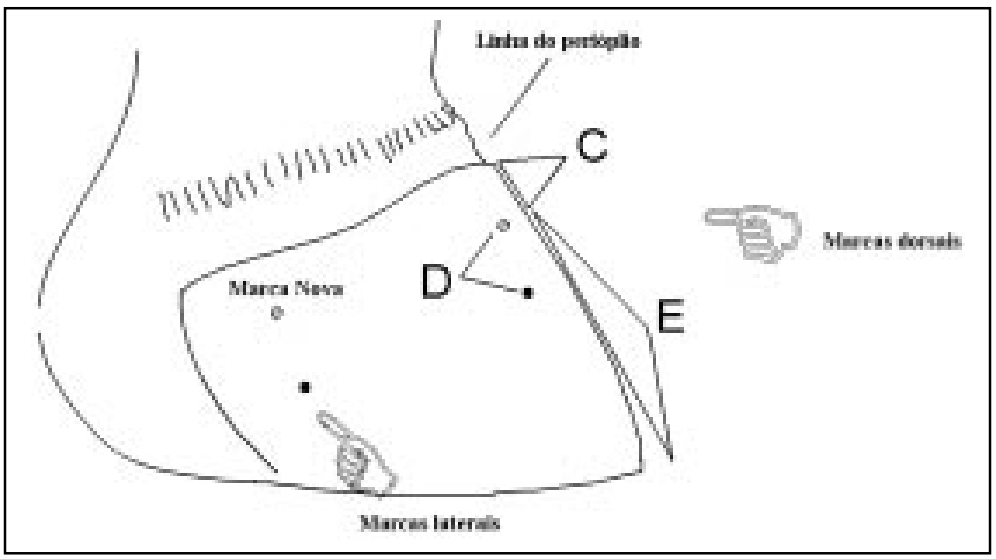

Figura 2 - Esquema da face lateral de casco bovino, na segunda marca realizada em janeiro de 1998 (marca subseqüente de abril segue o mesmo esquema). raças Jersey e Gir ( $p>0,72)$ e os membros anteriores e posteriores $(\mathrm{p}>0,32)$ (Tabela 1). Contudo, maiores crescimento $(p<0,001)$ e desgaste $(p<0,004)$ foram detectados na região lateral que na dorsal da mesma unha, em ambas as raças (Tabela 1).

Os resultados obtidos no $2^{\circ}$ experimento demonstram que a apara não interferiu no desgaste dos cascos, que se manteve inalterado. $\mathrm{O}$ crescimento, no entanto, foi bastante estimulado com o emprego da apara, em ambas as regiões dos cascos laterais $(\mathrm{p}<0,004)$ como nos cascos dos membros anteriores e posteriores $(\mathrm{p}<0,006)$ (Tabela 2). $2^{\mathrm{o}}$ Experimento - Foi verificada a influência de apara corretiva do estojo córneo sobre o crescimento e desgaste dos cascos de garrotes da raça Jersey. Logo após o término do primeiro experimento, foi realizada uma apara corretiva do estojo córneo, segundo os conceitos de KASARI (1991) e TOUSSAINT \& RAVEN (1973), onde foi retirada cerca de $0,5-1,0 \mathrm{~cm}$ da muralha axial e abaxial assim como quantidade suficiente de material da sola, a fim de manter a concavidade desta, não procedendo quaisquer correções na região do talão. Essas aparas foram realizadas tanto na unha lateral como na unha medial. A técnica, os procedimentos utilizados e os cálculos efetuados foram os mesmos empregados no primeiro experimento. Houve a necessidade de marcar-se o casco mais uma vez (em abril), pois a marcação realizada em novembro foi gradualmente desaparecendo.

As médias gerais, dentro e entre os tratamentos, foram avaliadas inicialmente por análise de variância (teste F). No caso de significância, as médias foram comparadas, entre si, pelo teste de Duncan. Os dados foram analisados com auxílio de um programa estatístico computadorizado MINITAB (1992).

\section{RESULTADOS}

Os resultados pertinentes à comparação das médias de crescimento e de desgaste obtidos no $1^{\circ}$ experimento estão apresentados na tabela 1. Não existiram diferenças significativas tanto no crescimento como no desgaste, quando comparadas as

\section{DISCUSSÃO}

O crescimento mensal médio dos cascos (0,41-0,42cm/mês), constatado neste trabalho (Tabela 1), independeu da raça e dos membros considerados e encontrou-se dentro dos valores padrões de bovinos hígidos, ou seja de 0,4 a $0,5 \mathrm{~cm} / \mathrm{mês}$ (VERMUNT \& GREENOUGH, 1995).

Os presentes resultados atestaram que não existiu influência racial $(\mathrm{p}>0,72)$ sobre o crescimento e o desgaste dos cascos (Tabela 1). Como o peso e a idade dos animais empregados eram semelhantes, assim como o manejo ambiental e dietético idêntico pode-se afirmar que nestas condições a taxa de reposição do tecido córneo foi idêntico entre os dois grupamentos raciais. Estes resultados confirmam a ausência de influência racial citada por VERMUNT \& GREENOUGH (1995) em revisão sobre o assunto.

Existiu uma pequena tendência numérica do crescimento médio dos cascos $(0,41 \mathrm{~cm} / \mathrm{mês})$ ser superior ao desgaste dos mesmos $(0,38 \mathrm{~cm} / \mathrm{mês})$

Tabela 1 - Influência racial da região da unha e de membro sobre o crescimento e desgaste normais do casco bovino.

\begin{tabular}{|c|c|c|c|c|c|c|}
\hline \multirow[t]{2}{*}{ Variável } & \multicolumn{2}{|c|}{ RAÇA } & \multicolumn{2}{|c|}{ REGIÃO } & \multicolumn{2}{|c|}{ MEMBRO } \\
\hline & Gir & Jersey & Lateral & Dorsal & Anterior & Posterior \\
\hline $\begin{array}{l}\text { Crescimento } \\
\text { (cm/mês) }\end{array}$ & $0,42 \pm 0,12^{\mathrm{a}}$ & $0,41 \pm 0,16^{\mathrm{a}}$ & $0,47 \pm 0,16^{\mathrm{a}}$ & $0,36 \pm 0,09^{b}$ & $0,41 \pm 0,16^{\mathrm{a}}$ & $0,42 \pm 0,12^{a}$ \\
\hline $\begin{array}{l}\text { Desgaste } \\
(\mathrm{cm} / \mathrm{mês})\end{array}$ & $0,38 \pm 0,15^{\mathrm{a}}$ & $0,38 \pm 0,24^{\mathrm{a}}$ & $0,45 \pm 0,23^{\mathrm{a}}$ & $0,31 \pm 0,14 b^{b}$ & $0,40 \pm 0,22^{a}$ & $0,35 \pm 0,17^{\mathrm{a}}$ \\
\hline
\end{tabular}

\footnotetext{
${ }^{\mathrm{a}, \mathrm{b}}$ Médias seguidas de diferentes letras na mesma coluna diferem estatisticamente $(\mathrm{P}<0,004)$.
} 
Tabela 2 - Influência da apara funcional do casco sobre o crecimento e desgaste do casco bovino em garrotes Jersey.

\begin{tabular}{|c|c|c|c|c|}
\hline \multirow[t]{2}{*}{ Variável } & \multicolumn{2}{|c|}{ REGIÃO } & \multicolumn{2}{|c|}{ MEMBRO } \\
\hline & LATERAL & DORSAL & ANTERIOR & POSTERIOR \\
\hline $\begin{array}{l}\text { Crescimento (cm/mês) } \\
\text { antes apara } \\
\text { após apara }\end{array}$ & $\begin{array}{l}0,48 \pm 0,18^{\mathrm{a}} \\
0,70 \pm 0,22^{\mathrm{b}}\end{array}$ & $\begin{array}{l}0,34 \pm 0,10^{\mathrm{a}} \\
0,59 \pm 0,15^{\mathrm{b}}\end{array}$ & $\begin{array}{l}0,40 \pm 0,18^{\mathrm{a}} \\
0,69 \pm 0,19^{\mathrm{b}}\end{array}$ & $\begin{array}{l}0,42 \pm 0,15^{\mathrm{a}} \\
0,60 \pm 0,19^{\mathrm{b}}\end{array}$ \\
\hline $\begin{array}{l}\text { Desgaste }(\mathrm{cm} / \mathrm{mês}) \\
\text { antes apara } \\
\text { após apara }\end{array}$ & $\begin{array}{l}0,38 \pm 0,24^{\mathrm{a}} \\
0,38 \pm 0,15^{\mathrm{a}}\end{array}$ & $\begin{array}{l}0,32 \pm 0,15^{\mathrm{a}} \\
0,25 \pm 0,20^{\mathrm{a}}\end{array}$ & $\begin{array}{l}0,39 \pm 0,13^{\mathrm{a}} \\
0,39 \pm 0,23^{\mathrm{a}}\end{array}$ & $\begin{array}{l}0,36 \pm 0,17^{\mathrm{a}} \\
0,31 \pm 0,19^{\mathrm{a}}\end{array}$ \\
\hline
\end{tabular}

a,b Médias seguidas de diferentes letras na mesma coluna diferem estatisticamente $(\mathrm{P}<0,006)$.

(Tabela 1). Isto também foi detectado por HAHN $\boldsymbol{e t}$ al. (1986), que constataram que essa diferença acentua-se quanto menor for a abrasividade do piso, e, por consequiência, menor o desgaste dos cascos. As médias de crescimento e desgaste dos cascos, detectadas neste experimento e supracitadas neste texto, foram semelhantes às descritas por MANSON \& LEAVER $(1988,1989)$ e TRANTER \& MORRIS (1992), porém ligeiramente inferiores às verificadas por CLARK \& RAKES (1982) e HAHN et al. (1986). Deve-se ressaltar que os autores destes dois últimos trabalhos citados utilizaram, na sua maioria, vacas holandesas mantidas em "free-stall" com piso abrasivo de concreto, que facilitava o desgaste dos cascos. Segundo HAHN et al. (1986), quanto maior for o desgaste dos cascos maior será o estímulo para o crescimento dos mesmos. No presente experimento, o desgaste dos cascos foi pequeno, já que os garrotes foram mantidos sobre espessa camada de maravalha, o que não proporcionava um atrito marcante.

Os presentes resultados confirmaram as conclusões de CLARK \& RAKES (1982), HAHN $\boldsymbol{e t}$ al. (1986) e DISTL et al. (1990) que ocorrem crescimento e desgaste maiores na região lateral do casco (lado abaxial), que na região dorsal (Tabela 1). Segundo DISTL et al. (1990), o maior contato do solo com a região lateral do estojo córneo facilita um maior desgaste do casco nesta área, o que estimula a ocorrência de um notório crescimento concomitante.

Não ocorreram diferenças no crescimento e desgaste dos cascos dos membros anteriores e posteriores ( $\mathrm{p}>0,32$ ) (Tabela 1), semelhante aos resultados descritos por CLARK \& RAKES (1982) e TRANTER \& MORRIS (1992) e diferentes dos observados por HAHN et al. (1986), que constataram maiores crescimento e desgaste nos membros posteriores que anteriores. Deve-se ressaltar que tais resultados foram obtidos em condições experimentais diferentes, ou seja, enquanto que no presente trabalho os animais foram mantidos em sistema de "tie-stall", os animais dos trabalhos citados anteriormente encontravam-se sob condições de pastejo, CLARK \& RAKES (1982) e TRANTER \& MORRIS (1992), ou em "free-stall", HAHN et al. (1986). Animais em estação distribuem o seu peso corporal de tal forma que os membros anteriores carregam, aproximadamente, $60 \%$ do peso e os membros posteriores o restante (FESSL 1968). Os membros posteriores têm como principal papel impulsionar o animal para frente (GREENOUGH \& WEAVER, 1997). Esse fato contribui para que cascos dos membros posteriores de animais em locomoção suportem maior peso, contribuindo para um maior desgaste do tecido córneo naquela região. $\mathrm{O}$ pasto é um terreno considerado mais próximo ao ambiente natural de um ruminante, portanto é de esperar que ocorram desgaste e crescimento uniformes dos cascos sob essas condições, como foi verificado por TRANTER \& MORRIS (1992).

Este estudo confirmou o efeito estimulante do crescimento dos cascos após suas aparas (Tabela 2), o que já havia sido descrito por MANSON \& LEAVER (1988, 1989). Esse resultado tem significado prático, pois é comum o tratamento dos cascos com a retirada dos tecidos córneos danificados. Tal manobra cirúrgica é adequada, pois além de extirpar áreas afetadas e em necrose, também estimula a regeneração e crescimento do casco hígido.

Novos trabalhos devem ser realizados para comparar o crescimento e o desgaste de cascos de bovinos de outras raças zebuínas e taurinas, usualmente criadas no Brasil, e submetidas a diferentes tipos de manejo zootécnico do aqui utilizado.

\section{REFERÊNCIAS BIBLIOGRÁFICAS}

CLARK, A.K., RAKES, A.H. Effect of methionine hydroxy supplementation on dairy cattle hoof growth and composition. J Dairy Sci v.65, p.1493-1502 1982.

DISTL, O., KRÄUSSLICH, H., MAIR, A., $\boldsymbol{e} t \boldsymbol{a l}$. Computergestützte Analyse von Druckverteilungsmessungen an Rinderklauen. Dtsch tierärztl Wschr, v.97, n.11, p.441508, 1990.

FESSL, L. Biometric studies on the ground surface of bovine claws and the distribution of the weight on the extremeties. $\mathbf{J}$ Vet Med A, v.15, p.844-860 1968. 
GREENOUGH, P.R., WEAVER, A.D. Lameness in cattle. Philadelphia, London, Toronto, Montreal, Sydney, Tokyo: Saunders, 1997. 324p.

HAHN, M.V., MCDANIEL, B.T., WILK, J.C. Rates of hoof growth and wear in Holstein cattle. J Dairy Sci, v.69, p.2148-2156, 1986.

KASARI, T.R. The principles of trimming the bovine hoof. Vet Med v.86, p.1218-1226, 1991.

MANSON, F.J., LEAVER, J.D. The influence of dietary protein intake and of hoof trimming on lameness in dairy cattle. Ani Prod, v.47, p.191-199, 1988 .

MANSON, F.J., LEAVER, J.D. The effect of concentrate: silage ration and of hoof trimming on lameness in dairy cattle. Ani Prod, v.49, p.15-22, 1989 .

MGASSA, M.N., MORTENSEN, K., MBASSA, G.K. The occurrence of bovine lameness in Tanzanian extensive and intensive dairy production systems. In: WORLD BUIATRICS CONGRESS 15, 1988, Palma de Mallorca. Proceedings... Palma de Mallorca, Spain : Associación de veterinarios espãnoles especilaistas en buiatria, 1988. p.1088-1094
MINITAB - The student edition of minitab statistical software adapted for education. 8 Release. New York : AddisonWesley, 1992. 624p. (User's Manual).

MURPHY, P.A., HANNAN, J. Effects of slatted flooring on claw shape in intesnively housed fattening beef cattle. INTERNATIONAL SYMPOSIUM ON DISORDERS OF THE RUMINANT DIGIT, 5. 1986, Dublin. Proceedings..., Dublin : n.1., 1986. p.2-7.

RIBEIRO, P.N., BORGES, J.R.J., RONCONI, M.A., et al. Incidência de afecções podais em bovinos de corte abatidos no Estado do Rio de Janeiro. Arq EMV-UFBA, v.15, p.2833, 1992.

TOUSSAINT RAVEN, E. Lameness in cattle and foot care. Netherlands J Vet Sci v.5, n.3, p.105-111, 1973.

TRANTER, W.P., MORRIS, R.S. Hoof growth and wear in pasture-fed dairy cattle. New Zeal Vet J, v.40, p.89-96, 1992.

VERMUNT, J.J., GREENOUGH, P.R. Structural characteristics of the bovine claw: Horn growth and wear, horn hardness and claw conformation. Br Vet J v.151, p.157-180, 1995.

Ciência Rural, v. 31, n. 1, 2001. 